\title{
DESEMPENHO AGRONÔMICO E ESTABILIDADE FENOTÍPICA DE HÍBRIDOS DE SORGO GRANÍFERO
}

\author{
JANEO EUSTÁQUIO DE ALMEIDA FILHO ${ }^{1}$, FLÁVIO DESSAUNE TARDIN ${ }^{2}$, SANDRO \\ ÂNGELO DE SOUZA ${ }^{3}$, VICENTE DE PAULO CAMPOS GODINHO ${ }^{4}$ e MILTON JOSÉ \\ $\mathrm{CARDOSO}^{5}$
}

\author{
${ }^{1}$ Discente de mestrado da Universidade Estadual do Norte Fluminense \\ (janeo.eustaquio@ymail.com) \\ ${ }^{2}$ Pesquisadorda Embrapa Milho e sorgo (tardin@cnpms.embrapa.br) \\ 3Docente da Universidade Luteranado Brasil (sandroasouza@yahoo.com.br) \\ ${ }^{4}$ Pesquisadorda Embrapa Rondônia (vgodinho@netview.com.br) \\ ${ }^{5}$ Pesquisadorda Embrapa Meio-Norte (miltoncardoso@cpamn.embrapa.br)
}

Revista Brasileira de Milho e Sorgo, v.9, n.1, p. 51-64, 2010

RESUMO - O sorgo granífero é uma das culturas que vêm apresentando significativo aumento de produtividade e área plantada no Brasil, com isso vem a importância de cultivares com rendimento estável. O trabalho teve o objetivo de avaliar o rendimento de grãos e a interação entre genótipos e ambiente (GxA) de 25 híbridos simples de sorgo granífero, em distintos ambientes. Para o estudo, foram conduzidos sete experimentos: um em Acreúna-GO, um em Itumbiara-GO, três com diferentes saturações por alumínio, em Sete Lagoas-MG, um em Vilhena-RO e um em Teresina-PI. Os experimentos seguiram o delineamento de blocos casualizados, com três repetições. Os genótipos avaliados foram: 0307401; 0090061; 0307363; 0307343; 0090035; 0307509; 0307421; 0307511; 0307541; 0577393; 0144015; 0307167; 0144013; 0307689; 9920045; 0307561; 0307671; 0577337; 0441347 e 0577335, esses provenientes do programa de melhoramento genético da Embrapa Milho e Sorgo e as cultivares comerciais 1G220; Dow 822; BRS 308; 1 G150 e BRS 310. Para a avaliação estatística, foi realizada a análise de variância e teste F. Para a realização de comparações múltiplas de médias, foi realizado o teste de Scott \& Knott (1974) e a estabilidade fenotípica foi mensurada pela análise de Annicchiarico (1992). O rendimento de grãos foi dependente do ambiente. Os híbridos 0307689, 0307671, 1G220 0307343, 1G150, 0307363, BRS 308, 0009061, 
9920045, BRS 310, 0307541 0441347, 0144015, 0307421 e 0307401,obtiveram destaque, por possuírem rendimento de grãos superior à média geral $\left(4,10\right.$ t.ha $\left.^{-1}\right)$ e apresentaram maior estabilidade fenotípica, considerando todos os ambientes.

Palavras chave: Sorghum bicolor, rendimento, interação GxA, melhoramento genético.

\title{
AGRONOMIC PERFORMANCE AND PHENOTYPIC STABILITY OF GRAIN SORGHUM HYBRIDS
}

\begin{abstract}
The sorghum is a crop that has shown significant increase in productivity and cultivated area in Brazil, because this is the importance of cultivars with stable yield. The study aimed to evaluate the yield and the interaction of genotype by environment (GE) of 25 grain sorghum hybrids in different environments. For this study were conducted seven experiments: one in Acreúna-GO, one in Itumbiara-GO, three with different saturation levels for aluminum in Sete Lagoas-MG, one in Vilhena-RO, and one in Teresina-PI. The experiments were in a randomized block design with three replications. The genotypes were: 0307401, 0090061, 0307363, 0307343, 0090035, 0307509, 0307421, 0307511, 0307541, 0577393, 0144015, 0307167, 0144013, 0307689, 9920045, 0307561, 0307671, 0577337, 0441347, 0577335, made by sorghum breeding program of the Embrapa Maize and Sorghum, and the commercial cultivars 1G220, Dow 822, BRS 308, BRS 310, and 1 G150. The statistical analysis was performed by variance analysis and $\mathrm{F}$ test. Was used the grouping of the average proposed by Scott and Knott (1974), and phenotypic stability was measured by analysis of Annicchiarico (1992). The yield was dependent on the environment. The hybrids, 0307689, 0307671, 1G220 0307343, 1G150, 0307363, BRS 308, 0009061, 9920045, BRS 310, 0307541 0441347, 0144015, 0307421 and 0307401, were prominence because to obtain grain yield were bigger than overall average (4.10 t ha-1) and showed greater phenotypic stability when considered all environments.
\end{abstract}

Key words: Sorghum bicolor, income, GE interaction, genetic breeding. 
A crescente demanda por grãos no mundo, associada ao substancial incremento genético dos híbridos, tem alavancado, a cada ano, a área plantada e a produtividade da cultura do sorgo, no Brasil. Nos últimos três anos, o cereal que apresentou maior incremento médio em produtividade, decorrente da melhoria genética foi, sem dúvida nenhuma, o sorgo granífero que atrai, a cada ano, mais agricultores empresariais buscando a sua boa rentabilidade no sistema produtivo (Figueiredo, 2007).

A grande expansão do cultivo do sorgo granífero, principalmente em plantios de sucessão a culturas de verão, tem gerado grande demanda por cultivares produtivas e com valor agregado para adaptação às condições predominantes nas regiões de plantio (Santos et al., 2007).

$\mathrm{Na}$ época em que ocorre o desenvolvimento da segunda safra, o volume e a frequência de chuvas costumam ser oscilantes e insuficientes. Pelas suas características xerófitas, o sorgo apresenta potencial em plantio de sucessão. Segundo Magalhães et al. (2009), o sorgo é mais eficiente que o milho e o trigo na conversão de água em matéria seca e é dotado de importantes mecanismos bioquímicos e morfológicos que lhe conferem tolerância a seca

Para ser recomendada, uma cultivar deve apresentar desempenho consistentemente superior em uma série de ambientes. Portanto, no estádio final de um programa de melhoramento, torna-se fundamental a avaliação do comportamento das cultivares obtidas em vários anos e locais (Oliveira et al., 2002).

Os rendimentos médios mais elevados nos locais de teste são utilizados, na maioria das vezes, como critério de recomendação das cultivares. Porém, a indicação generalizada, sem considerar que existem ambientes favoráveis e desfavoráveis, pode beneficiar ou prejudicar as cultivares com adaptações específicas a esses dois tipos de ambientes (Carneiro, 1998).

São observadas diversas metodologias empregadas em estudos de estabilidade, as quais são amplamente discutidas e distinguem-se pelos conceitos de estabilidade, adaptabilidade e princípios estatísticos empregados (Cruz \& Regazzi, 2001). As metodologias baseadas na análise de regressão alcançaram bastante popularidade, cujo exemplo clássico é fornecido por Eberhart \& Russell (1966). Entretanto, existem métodos em que os procedimentos são baseados na análise de variância e as estimativas do parâmetro de estabilidade são expressas em componentes quadráticos, quadrados médios ou componentes da variância. Os exemplos das metodologias que empregam esse procedimento são aquelas desenvolvidas por Wricke (1965) e Annicchiarico (1992), as quais são alternativas mais simples para 
comparar a performance de cultivares em situações de interação $\mathrm{G}$ x A significativa (Scapim et al., 2000).

A metodologia do uso do índice de risco, proposta por Annicchiarico (1992), tem destaque, por ser de fácil aplicação. O índice de risco refere-se a um parâmetro de avaliação da estabilidade fenotípica e é estimado nessa metodologia. A proposta é que se considere um coeficiente de confiança de $75 \%$ e que as médias genotípicas sejam expressas em termos da porcentagem dos valores médios dos ambientes. Posteriormente, estimam-se, com os dados dessa forma padronizados, a média e o desvio-padrão de cada genótipo em relação aos ambientes. Utilizando-se esses valores e adotando-se a distribuição normal como modelo, os índices de risco são estimados, os quais fornecem a representação de uma probabilidade de confiança, da proporção mínima que um determinado genótipo supera a média dos ambientes estudados. Quanto maior o valor do índice de risco, mais estável será considerado o genótipo (Abreu et al., 2004).

A vantagem da metodologia proposta por Annicchiarico (1992) está no fato de que a seleção de determinada cultivar para os agricultores é feita considerando-se o risco de a mesma ter desempenho inferior a um padrão previamente escolhido, geralmente a cultivar com maior uso em determinada região de cultivo (Elias et al., 2005).

O objetivo deste trabalho foi avaliar o rendimento de grãos de diferentes híbridos simples de sorgo granífero em diferentes ambientes e a interação GxA, por meio da análise de estabilidade fenotípica proposta por Annicchiarico (1992).

\section{Material e Métodos}

\section{Descrição dos experimentos}

Foram conduzidos sete experimentos: um em Acreúna-GO, um em Itumbiara-GO, três em Sete Lagoas-MG (os ambientes de Sete Lagoas foram denominados Sete Lagoas 1, 2 e 3, com níveis de saturação por alumínio de 0, 20 e 40\% respectivamente), um em Vilhena-RO e um em Teresina-PI. Nos municípios avaliados, existem consideráveis variações geográficas (Tabela 1) e com distintas condições ambientais (Figura 1). Os experimentos seguiram o delineamento de blocos ao acaso, com três repetições. As parcelas experimentais foram compostas por quatro linhas de $5 \mathrm{~m}$, com espaçamento de 0,5 $m$ entre linhas, sendo que apenas as duas fileiras centrais foram consideradas como parcela. Foi plantada uma linha com sorgo paralela aos blocos, com distância de 0,5 m do mesmo, para servir de bordadura às parcelas da extremidade do bloco. Foram avaliados 25 genótipos, sendo 20 provenientes do programa de melhoramento da Embrapa Milho e Sorgo e cinco híbridos comerciais. Os genótipos avaliados foram, respectivamente: 0307401; 0090061; 0307363; 
TABELA 1. Descrição geográfica dos municípios onde foram implantados os experimentos.

\begin{tabular}{lccc}
\hline Ambientes & Altitude (m) & Latitude (S) & Longitude (O) \\
\hline Acreúna & 650 & $17^{\circ} 23^{\prime} 45^{\prime \prime}$ & $50^{\circ} 22^{\prime} 37^{\prime \prime}$ \\
Itumbiara & 448 & $18^{\circ} 26^{\prime} 00^{\prime \prime}$ & $49^{\circ} 13^{\prime} 00^{\prime \prime}$ \\
Sete Lagoas & 767 & $19^{\circ} 27^{\prime} 57^{\prime \prime}$ & $44^{\circ} 14^{\prime} 49^{\prime \prime}$ \\
Teresina & 72 & $05^{\circ} 05^{\prime} 20^{\prime \prime}$ & $42^{\circ} 48^{\prime} 07^{\prime \prime}$ \\
Vilhena & 600 & $12^{\circ} 44^{\prime} 26^{\prime \prime}$ & $60^{\circ} 08^{\prime} 45^{\prime \prime}$ \\
\hline
\end{tabular}

Fonte: IBGE, 2010

0307343; 0090035; 0307509; 0307421; após o plantio.

0307511; 0307541; 0577393; 0144015; No experimento de Itumbiara, a adubação 0307167; 0144013; 0307689; 9920045; foi realizada em função da análise de solo, de 0307561;0307671;0577337;0441347;0577335 acordo com a metodologia proposta por Alves 1G220; 1G150; BRS 308; BRS 310 e Dow 822. et al. (1999) para a cultura do sorgo granífero.

\section{Manejo}

Com exceção dos ambientes Sete Lagoas 2 e Sete Lagoas 3, foi realizada calagem com base na análise de solo.

Nas adubações dos experimentos de Acreúna e Teresina utilizaram-se 60-60-45 $\mathrm{Kg} \mathrm{ha}^{-1}$ de $\mathrm{N}, \mathrm{P}_{2} \mathrm{O}_{5}$ e $\mathrm{K}_{2} \mathrm{O}$, respectivamente. A adubação de nitrogênio foi parcelada em duas épocas, um terço no plantio e os dois terços restantes em cobertura, na forma de uréia, de 30 a 35 dias após a emergência.

Em Vilhena, foi realizada adubação com $300 \mathrm{~kg} \mathrm{ha}^{-1}$ do formulado NPK 05-25-15, no plantio, e $31,5 \mathrm{Kg} \mathrm{ha}^{-1}$ de $\mathrm{N}$ em cobertura na forma ureia, aos 20 dias após a semeadura. Nos ambientes de Sete Lagoas, utilizaram-se, no plantio, $280 \mathrm{~kg} \mathrm{ha}^{-1}$ da formulação NPK 08-2816 e $200 \mathrm{~kg} \mathrm{ha}^{-1}$ de ureia em cobertura, 25 dias Desse modo, foram utilizados 60,40 e $40 \mathrm{~kg}$ ha $^{-1}$, respectivamente de $\mathrm{N}, \mathrm{P}_{2} \mathrm{O}_{5}$ e $\mathrm{K}_{2} \mathrm{O}$, na forma de ureia, superfosfato simples e cloreto de potássio. $\mathrm{O} \mathrm{N}$ foi parcelado em duas épocas, um terço no plantio e os dois terços restantes em cobertura, de 30 a 35 dias após a emergência. A semeadura foi realizada no sistema de plantio direto na primeira quinzena de março, em todos os experimentos, com densidade populacional de aproximadamente 200.000 plantas ha ${ }^{-1}$.

A irrigação foi realizada apenas para a obtenção do estande inicial, depois foi cortada, atendendo ao objetivo de proporcionar condições climáticas semelhantes às que ocorrem na safrinha, em cada ambiente, com exceção de Itumbiara, onde, devido à baixa incidência de chuvas, o experimento foi irrigado toda vez que as folhas começaram a

Revista Brasileira de Milho e Sorgo, v.9, n.1, p. 51-64, 2010

Versão impressa ISSN 1676-689X / Versão on line ISSN 1980-6477 - http://www.abms.org.br 


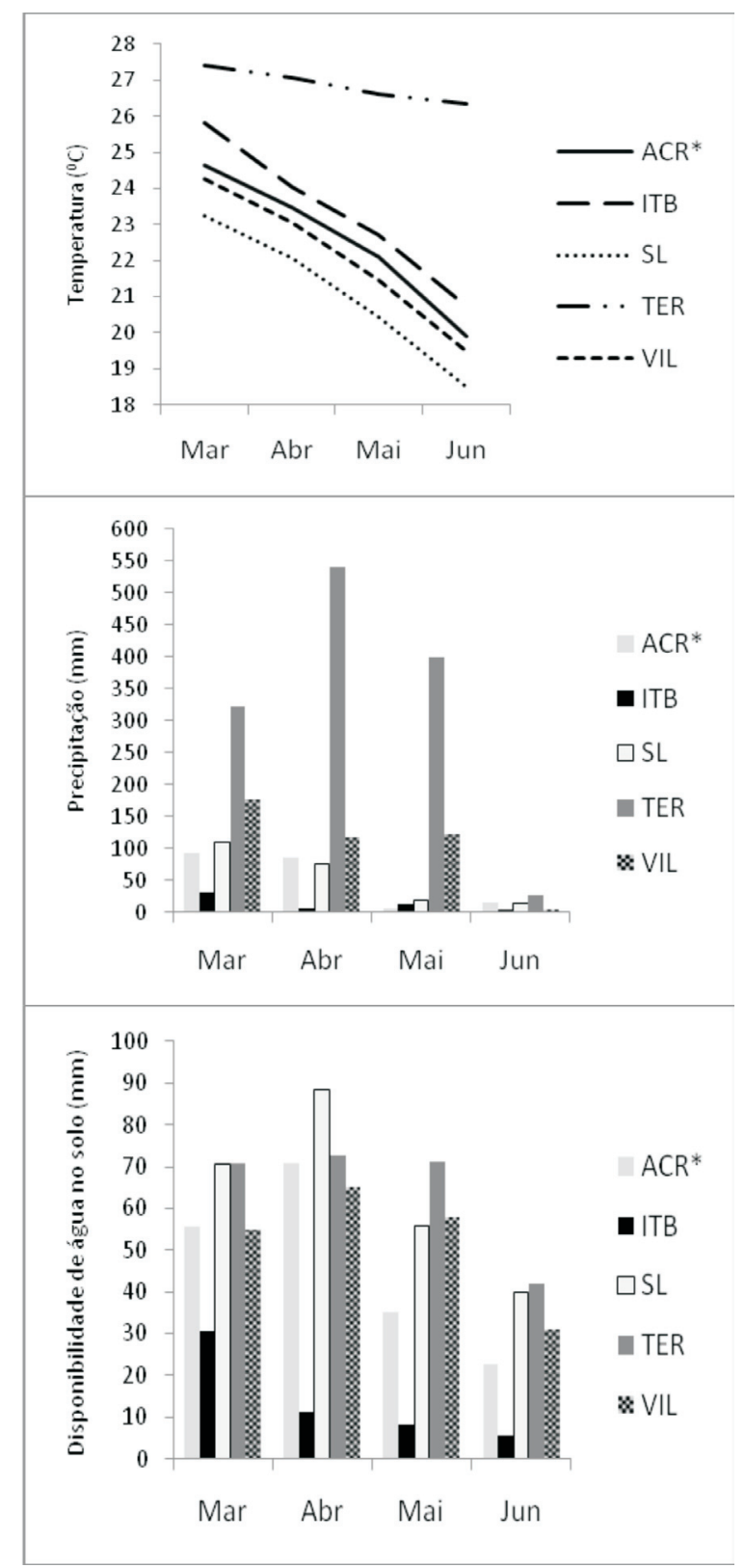

FIGURA 1. Dados pluviométricos, de temperatura e água disponível no solo, nos ambientes estudados. Fonte: Agritempo, sendo as estações meteorológicas Inmet em Itumbiara (ITB), Sete Lagoas (SL) e Teresina (TER); Cemig em Acreúna (ACR) e Cptec em Vilhena (VIL).

*Estação meteorológica localizada no município de Paraúna, a menos de 50 km do experimento em Acreúna. 
se enrolar.

O manejo de lagartas foi realizado com inseticidas do grupo químico organofosforado ou piretróide. O manejo de formigas cortadeiras foi realizado com iscas granuladas à base de laranja e princípio ativo do grupo organofosforado. Os produtos foram utilizados segundo dosagem recomendadas pelo fabricante. O controle dos pássaros foi realizado com a cobertura das panículas com sacolas Kraft de capacidade de $5 \mathrm{~kg}$. Não foi realizado controle químico de doenças, uma vez que a principal medida de controle é o uso de cultivares resistentes.

Para a avaliação do rendimento de grãos, foram colhidas todas as plantas da área útil, as quais foram trilhadas, e corrigiu-se a umidade desses grãos para $13 \%$.

\section{Análises estatísticas}

A avaliação estatística dos dados foi realizada inicialmente com a análise de variância e teste F, considerando apenas o ambiente onde houve a observação, de acordo com o seguinte modelo matemático para análise de variância: $Y_{\mathrm{ij}}$ $=\mu+g_{i}+b_{j}+e_{i j ;}$ em que: $Y_{i j}=$ observação feita na parcela do i-ésimo tratamento no j-ésimo bloco; $\mu=$ média geral; $\quad g_{\mathrm{i}}=$ efeito do i-ésimo genótipo; $b_{j}=$ efeito do $\mathrm{j}$-ésimo bloco; $\mathrm{e}_{\mathrm{ij}}=$ efeito dos fatores não controlados na parcela que recebeu o i-ésimo genótipo no j-ésimo bloco.

Para a avaliação da interação GxA, foi realizada a análise de variância conjunta, pelo seguinte modelo matemático: $\mathrm{Y}_{\mathrm{ijk}}=\mu+\mathrm{g}_{\mathrm{i}}+\mathrm{a}_{\mathrm{j}}+$ $\mathrm{ga}_{\mathrm{ij}}+\mathrm{b}_{\mathrm{k}} / \mathrm{a}_{\mathrm{j}}+\mathrm{e}_{\mathrm{ijk} ;}$ em que: $\mathrm{Y}_{\mathrm{ijk}}=$ observação feita na parcela do i-ésimo tratamento no j-ésimo bloco; $\mu=$ média geral; $\mathrm{g}_{\mathrm{i}}=$ efeito do i-ésimo genótipo; $\mathrm{a}_{\mathrm{j}=}$ efeito do $\mathrm{j}$-ésimo ambiente; $g \mathrm{a}_{\mathrm{i} j}=$ efeito de interção do i-ésimo genótipo com o j-ésimo ambiente; $b_{k} / a_{j}=$ efeito do k-ésimo bloco dentro do j-ésimo ambiente; $\mathrm{e}_{\mathrm{ijk}}=$ efeito dos fatores não controlados na parcela que recebeu o i-ésimo genótio no j-ésimo ambiente dentro do k-ésimo bloco.

As análises de variância e testes $\mathrm{F}$ foram realizadas com o auxílio do software Microsoft Excel, segundo Banzato \& Kronka (1992). Para o agrupamento de médias dos genótipos, foi utilizado o teste de Scott e Knott (1976), utilizando o programa Genes (Cruz, 2006).

Uma vez constatada a presença de interação GxA (teste F significativo), procedeuse à análise de estabilidade fenotípica proposta por Annicchiarico (1992). Para a aplicação dessa metodologia, primeiramente foram calculadas as médias dos ambientes e, em seguida, obtiveram-se as porcentagens das cultivares em relação às médias dos ambientes. Depois calcularam-se as médias de cada genótipo, em porcentagem, e o desvio-padrão dessas médias. Por sua vez, o parâmetro de estabilidade $(\mathrm{I} i)$, ou índice de confiança, foi estimado pela seguinte equação: $I_{i}=Y_{i}-Z_{(1-\alpha)} s_{i}$; em que: $O Y_{i}$ é o valor percentual médio do i-ésimo genótipo em 
relação à média do ambiente em questão; $Z_{(1-\alpha)}$ é o valor na distribuição normal estandardizada no qual a função de distribuição acumulada atinge o valor (1- $\alpha$ ). Esse $\alpha$ é o nível de significância que, nesse caso, foi adotado, 0,25, e $s_{\mathrm{i}}$ é o desvio-padrão das porcentagens de cada genótipo. Segundo Cruz \& Carneiro (2003) não esta claro qual o melhor nível de significância a ser adotado, esses autores recomendam $\alpha=$ 0,25 , com isso $\mathrm{Z}_{(1-\alpha)}=\mathrm{P}(0 \leq \mathrm{u} \leq 0,75)=0,2734$.

\section{Resultados e Discussão}

Para rendimento de grãos, foi observada diferença significativa entre os genótipos em todos os sete ambientes avaliados e o controle local não foi efetivo (não existe diferença significativa entre os blocos), apenas nos ambientes Itumbiara e Sete Lagoas 3 (Tabela 2).
Como a razão entre o maior e o menor quadrado médio do resíduo obtido nos diferentes ambientes foi inferior a sete, foi possível realizar a análise de variância conjunta (Banzato \& Kronca, 1992). Nesta, foi observada a interação entre genótipos e ambientes $(\mathrm{p}<0,01)$, bem como diferenças significativas entre os genótipos e entre os ambientes $(\mathrm{p}<0,01)$ (Tabela 3$)$.

A análise do rendimento de grãos mostrou que, em Itumbiara, o genótipo 0307167 se destacou com média de 7,00 t.ha ${ }^{-1}$, em Acreúna, que se localiza a $226 \mathrm{~km}$ de Itumbiara, esse genótipo teve média de apenas 3,71 t.ha-1, um baixo desempenho em relação aos outros genótipos, em Acreúna. Em Acreúna, o genótipo 0307401 apresentou o melhor desempenho, com média de 6,19 t.ha-1 esse mesmo genótipo apresentou média de 4,43

TABELA 2. Resumo das análises de variância para rendimento de grãos de 25 híbridos de sorgo cultivados nos ambientes de Acreúna (ACR), Itumbiara (ITB), Sete Lagoas 1 (SL1), Sete Lagoas 2 (SL2), Sete Lagoas 3 (SL3), Teresina (TER) e Vilhena (VIL), 2009.

\begin{tabular}{lcllllllc}
\hline \multirow{2}{*}{ F.V. } & \multirow{2}{*}{ G.L. } & \multicolumn{7}{c}{ Q.M. } \\
\cline { 3 - 8 } & & ACR & ITB & SL1 & SL2 & SL3 & VIL & TER \\
\hline Genótipos & 24 & $1,96^{* *}$ & $2,42^{* *}$ & $2,20^{* *}$ & $2,64^{* *}$ & $3,76^{* *}$ & $5,16^{* *}$ & $0,65^{*}$ \\
Blocos & 2 & $2,07^{* *}$ & $1,61 \mathrm{~ns}$ & $2,40^{* *}$ & $1,70^{*}$ & $0,10 \mathrm{~ns}$ & $1,38^{*}$ & $1,01^{* *}$ \\
Resíduo & 48 & 0,73 & 0,83 & 0,93 & 0,81 & 0,51 & 0,32 & 0,33 \\
Total & 74 & & & & & & & \\
\hline C.V. $(\%)$ & & 19,00 & 17,80 & 20,70 & 19,74 & 18,76 & 15,39 & 23,95 \\
\hline
\end{tabular}

$\mathrm{ns}, *$ e **: Não significativo, significativo a $5 \%$ e $1 \%$ pelo teste $\mathrm{F}$, respectivamente.

Revista Brasileira de Milho e Sorgo, v.9, n.1, p. 51-64, 2010

Versão impressa ISSN 1676-689X / Versão on line ISSN 1980-6477 - http://www.abms.org.br 
TABELA 3. Resumo da análise de variância conjunta para rendimento de grãos de 25 híbridos de sorgo cultivados nos ambientes de Acreúna, Itumbiara, Sete Lagoas 1, Sete Lagoas 2, Sete Lagoas 3, Vilhena e Teresina, 2009.

\begin{tabular}{lccr}
\hline F.V. & G.L. & S.Q. & Q.M. \\
\hline Genótipos (G) & 24 & 180,98 & $7,54 * *$ \\
Ambientes (A) & 6 & 362,69 & $60,45 * *$ \\
GxA & 144 & 270,09 & $1,88 * *$ \\
Blocos/Ambientes & 14 & 20,54 & 1,47 \\
Resíduo & 336 & 4,46 & 0,01 \\
Total & 524 & 838,76 & \\
\hline C.V.(\%) & & & 2,81 \\
\hline
\end{tabular}

**: Significativo a $1 \%$ pelo teste $\mathrm{F}$.

t.ha-1 em Itumbiara, que foi uma média menor que a de todos os genótipos nesse ambiente.

A oscilação de desempenho entre os genótipos, nos ambientes Itumbiara e Acreúna, é normal, pois o manejo de irrigação foi diferente, além de Acreúna ter maior altitude, acarretando menores temperaturas nesse local.

Em Sete Lagoas, os genótipos 1G150 e 0307671 se destacaram. O 1 G150 foi o mais produtivo no ambiente Sete Lagoas 2 e segundo mais produtivo no ambiente Sete Lagoas 3, com médias de 6,46 e 5,65 t.ha ${ }^{1}$ respectivamente; o 0307671 foi o mais produtivo nos ambientes Sete Lagoas 1 e Sete Lagoas 3 e o segundo mais produtivo no ambiente Sete Lagoas 2, com médias de 6,62, 5,90 e 6,24 t.ha , $^{-1}$ respectivamente. Os genótipos com destaque nos ambientes
Sete Lagoas 2 e 3 podem ser considerados tolerantes ao alumínio tóxico. Em Teresina, a cultivar comercial 1G220 apresentou a maior produtividade média $\left(3,85\right.$ t.ha $\left.{ }^{-1}\right)$, diferindo estatisticamente dos demais. Os genótipos 0307509 e 0577337 apresentaram os piores rendimentos de grãos, com respectivas médias de 1,82 e 1,69 t.ha ${ }^{-1}$, não diferindo entre si e se diferindo estatisticamente dos demais genótipos. Em Vilhena, a produtividade variou de 5,62 a 0,67 t.ha-1 ${ }^{-1}$ com os respectivos genótipos BRS 308 e 577337, ambos diferindo estatisticamente dos demais (Tabela 4).

O rendimento de grãos variou entre 0,67 a 7,0 t.ha-1e a média geral foi de 4,1 t.ha-1. A produtividade foi significativamente superior à produtividade média brasileira eà média da região em que os ensaios foram conduzidos. Segundo o IBGE (2010), em 2009, a produtividade de 
TABELA 4. Médias de rendimento de grãos $\left(\mathrm{Kg}_{\mathrm{g}} \mathrm{ha}^{-1}\right)$ de 25 genótipos de sorgo cultivados nos ambientes Sete Lagoas 1 (SL1), Sete Lagoas 2 (SL2), Sete Lagoas 3 (SL3), Itumbiara (ITB), Vilhena (VIN), Acreúna (ACR) e Teresina (TER) e de todos os ambientes, para cada genótipo, para rendimento de grãos em t.ha ${ }^{-1}, 2009$.

\begin{tabular}{|c|c|c|c|c|c|c|c|c|c|c|c|c|c|c|c|c|c|c|c|c|c|c|}
\hline \multirow{3}{*}{$\begin{array}{l}\text { Genótipos } \\
0307689\end{array}$} & \multicolumn{21}{|c|}{ Ambientes } & \multirow{3}{*}{$\begin{array}{r}\text { Médias } \\
5,09\end{array}$} \\
\hline & \multicolumn{3}{|c|}{ ITB } & \multicolumn{3}{|c|}{ SL1 } & \multicolumn{3}{|c|}{ SL2 } & \multicolumn{3}{|c|}{ ACR } & \multicolumn{3}{|c|}{ SL3 } & \multicolumn{3}{|c|}{ VIN } & \multicolumn{3}{|c|}{ TER } & \\
\hline & 6,58 & $\mathrm{~B}$ & $a^{*}$ & 6,13 & B & $\mathrm{b}$ & 5,84 & $\mathrm{C}$ & $\mathrm{c}$ & 5,05 & E & d & 4,88 & E & $\mathrm{d}$ & 4,31 & $\mathrm{E}$ & , & 2,84 & B & $\mathrm{f}$ & \\
\hline 0307671 & 5,46 & $\mathrm{E}$ & $\mathrm{d}$ & 6,62 & $\Delta$ & $\mathrm{a}$ & 6,24 & $\mathrm{~b}$ & $\mathrm{~b}$ & 3,67 & $\mathrm{~J}$ & $\mathrm{f}$ & 5,90 & A & $\mathrm{c}$ & 5,13 & $\mathrm{C}$ & 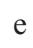 & 2,44 & D & $\mathrm{g}$ & 5,07 \\
\hline $1 \mathrm{G} 220$ & 6,26 & $\mathrm{C}$ & $\mathrm{a}$ & 5,43 & D & $\mathrm{c}$ & 5,70 & $\mathrm{C}$ & $\mathrm{b}$ & 5,27 & $\mathrm{D}$ & $\mathrm{c}$ & 3,56 & I & $\mathrm{f}$ & 4,55 & $\mathrm{D}$ & & 3,85 & A & 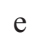 & 4,95 \\
\hline 0307343 & 6,07 & $\mathrm{C}$ & $\mathrm{a}$ & 5,79 & $\mathrm{C}$ & $\mathrm{b}$ & 4,96 & $\mathrm{E}$ & $\mathrm{d}$ & 5,29 & $\mathrm{D}$ & $\mathrm{c}$ & 4,51 & $\mathrm{~F}$ & e & 5,00 & $\mathrm{C}$ & $\mathrm{u}$ & 2,16 & $\mathrm{E}$ & $\mathrm{f}$ & 4,82 \\
\hline $1 \mathrm{G} 150$ & 5,12 & $\mathrm{~F}$ & $\mathrm{c}$ & 4,79 & G & $\mathrm{d}$ & 6,46 & A & $\mathrm{a}$ & 4,02 & I & e & 5,65 & B & $\mathrm{b}$ & 3,92 & G & 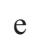 & 2,03 & $\mathrm{~F}$ & 1 & 4,57 \\
\hline 0009061 & 5,65 & $\mathrm{D}$ & $\mathrm{a}$ & 3,69 & $\mathrm{~J}$ & $\mathrm{e}$ & 4,60 & $\mathrm{~F}$ & $\mathrm{c}$ & 5,65 & $\mathrm{C}$ & $\mathrm{a}$ & 5,40 & $\mathrm{C}$ & $\mathrm{b}$ & 4,12 & $\mathrm{~F}$ & $\mathrm{u}$ & 2,18 & E & $\mathrm{f}$ & 4,47 \\
\hline 0307363 & 4,48 & $\mathrm{H}$ & $\mathrm{c}$ & 5,01 & $\mathrm{~F}$ & $\mathrm{~b}$ & 5,81 & $\mathrm{C}$ & $\mathrm{a}$ & 4,51 & G & $\mathrm{c}$ & 4,43 & $\mathrm{~F}$ & $\mathrm{c}$ & 4,05 & $\mathrm{~F}$ & $\mathrm{u}$ & 2,83 & B & $\mathrm{e}$ & 4,45 \\
\hline BRS 308 & 3,24 & $\mathrm{~K}$ & $\mathrm{e}$ & 3,93 & I & $\mathrm{d}$ & 4,73 & $\mathrm{~F}$ & $\mathrm{c}$ & 4,56 & G & $\mathrm{c}$ & 5,19 & $\mathrm{D}$ & $\mathrm{b}$ & 5,62 & A & $\mathrm{a}$ & 2,93 & B & & 4,32 \\
\hline 0307541 & 5,31 & $\mathrm{E}$ & $\mathrm{a}$ & 5,17 & E & $\mathrm{a}$ & 4,68 & $\mathrm{~F}$ & $\mathrm{~b}$ & 4,83 & $\mathrm{~F}$ & $\mathrm{~b}$ & 3,38 & $\mathrm{~J}$ & $\mathrm{~d}$ & 4,39 & $\mathrm{E}$ & $\mathrm{c}$ & 2,19 & E & $\mathrm{e}$ & 4,28 \\
\hline 0144015 & 5,02 & $\mathrm{~F}$ & $\mathrm{~b}$ & 4,88 & G & $\mathrm{b}$ & 4,31 & $\mathrm{H}$ & $\mathrm{c}$ & 5,43 & $\mathrm{D}$ & $\mathrm{a}$ & 4,25 & G & $\mathrm{c}$ & 3,65 & $\mathrm{H}$ & d & 2,12 & E & $c$ & 4,24 \\
\hline BRS 310 & 4,51 & $\mathrm{H}$ & $\mathrm{c}$ & 4,70 & G & $\mathrm{b}$ & 4,08 & I & $\mathrm{d}$ & 5,97 & B & $\mathrm{a}$ & 3,70 & I & $\mathrm{e}$ & 3,86 & G & $\mathrm{e}$ & 2,71 & $\mathrm{C}$ & $\mathrm{f}$ & 4,21 \\
\hline 0441347 & 4,73 & G & $\mathrm{b}$ & 5,24 & E & $\mathrm{a}$ & 4,52 & G & $\mathrm{c}$ & 4,14 & $\mathrm{H}$ & $\mathrm{d}$ & 3,96 & $\mathrm{H}$ & $\mathrm{d}$ & 4,10 & $\mathrm{~F}$ & $\mathrm{u}$ & 2,55 & $\mathrm{C}$ & $\mathrm{f}$ & 4,18 \\
\hline 9920045 & 5,35 & $\mathrm{E}$ & $\mathrm{a}$ & 3,78 & I & $\mathrm{e}$ & 3,96 & I & $\mathrm{d}$ & 4,81 & $\mathrm{~F}$ & $\mathrm{~b}$ & 3,74 & I & $\mathrm{e}$ & 4,56 & $\mathrm{D}$ & 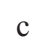 & 3,03 & B & $\mathrm{f}$ & 4,18 \\
\hline 0307421 & 4,15 & I & $\mathrm{d}$ & 5,05 & $\mathrm{f}$ & $\mathrm{b}$ & 4,41 & $\mathrm{G}$ & $\mathrm{c}$ & 4,28 & $\mathrm{H}$ & $\mathrm{d}$ & 3,58 & I & $\mathrm{e}$ & 5,30 & B & $a$ & 2,16 & $\mathrm{E}$ & $\mathrm{f}$ & 4,13 \\
\hline 0307167 & 7,00 & A & $\mathrm{a}$ & 3,66 & $\mathrm{~F}$ & $\mathrm{~d}$ & 5,35 & $\mathrm{D}$ & $\mathrm{b}$ & 3,71 & $\mathrm{~J}$ & $\mathrm{~d}$ & 4,49 & $\mathrm{~F}$ & $\mathrm{c}$ & 1,76 & $\mathrm{~L}$ & I & 2,72 & $\mathrm{C}$ & $\mathrm{e}$ & 4,10 \\
\hline 0307401 & 4,43 & $\mathrm{H}$ & $\mathrm{b}$ & 3,87 & I & $\mathrm{d}$ & 4,11 & I & $\mathrm{c}$ & 6,19 & A & $\mathrm{a}$ & 3,23 & $\mathrm{~K}$ & $\mathrm{e}$ & 4,59 & $\mathrm{D}$ & 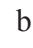 & 2,24 & $\mathrm{E}$ & $\mathrm{f}$ & 4,10 \\
\hline 0144013 & 4,68 & G & $\mathrm{b}$ & 5,20 & E & $\mathrm{a}$ & 3,92 & I & $\mathrm{d}$ & 4,22 & $\mathrm{H}$ & $\mathrm{c}$ & 4,35 & $\mathrm{~F}$ & $\mathrm{c}$ & 4,17 & $\mathrm{~F}$ & & 2,12 & $\mathrm{E}$ & $\mathrm{e}$ & 4,09 \\
\hline 0307511 & 5,59 & $\mathrm{D}$ & $\mathrm{a}$ & 5,53 & $D$ & $\mathrm{a}$ & 4,35 & $\mathrm{H}$ & $\mathrm{b}$ & 4,38 & G & $\mathrm{b}$ & 2,28 & M & $\mathrm{d}$ & 2,67 & $\mathrm{~J}$ & & 1,92 & $\mathrm{~F}$ & $\mathrm{e}$ & 3,82 \\
\hline 0307561 & 3,96 & $\mathrm{~J}$ & $\mathrm{c}$ & 4,35 & $\mathrm{H}$ & $\mathrm{b}$ & 4,24 & $\mathrm{H}$ & $\mathrm{b}$ & 4,53 & G & $\mathrm{a}$ & 2,84 & $\mathrm{~L}$ & $\mathrm{~d}$ & 4,38 & $\mathrm{E}$ & b & 2,38 & D & $\mathrm{e}$ & 3,81 \\
\hline Dow 822 & 4,48 & $\mathrm{~F}$ & $\mathrm{a}$ & 4,28 & $\mathrm{H}$ & $\mathrm{b}$ & 3,72 & $\mathrm{~J}$ & d & 4,03 & I & $\mathrm{c}$ & 3,48 & $\mathrm{~J}$ & $\mathrm{e}$ & 3,42 & I & 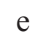 & 2,66 & $\mathrm{C}$ & $\mathrm{f}$ & 3,72 \\
\hline 0577335 & 5,38 & $\mathrm{E}$ & $\mathrm{a}$ & 3,84 & I & d & 4,62 & $\mathrm{~F}$ & $\mathrm{~b}$ & 4,15 & $\mathrm{H}$ & $\mathrm{c}$ & 2,31 & IVI & $\mathrm{e}$ & 2,20 & $\mathrm{~K}$ & 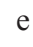 & 2,22 & E & $\mathrm{e}$ & 3,53 \\
\hline 0577393 & 5,39 & $\mathrm{D}$ & $\mathrm{a}$ & 4,37 & $\mathrm{H}$ & b & 3,75 & $\mathrm{~J}$ & $\mathrm{c}$ & 3,72 & $\mathrm{~J}$ & $\mathrm{c}$ & 2,51 & $\mathrm{M}$ & $\mathrm{d}$ & 2,21 & $\mathrm{~K}$ & 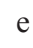 & 2,47 & $\mathrm{D}$ & $d$ & 3,49 \\
\hline 0307509 & 5,22 & $\mathrm{~F}$ & $\mathrm{a}$ & 3,65 & $\mathrm{~J}$ & b & 3,42 & $\mathrm{~K}$ & $\mathrm{c}$ & 3,10 & K & $\mathrm{d}$ & 2,94 & $\mathrm{~L}$ & $\mathrm{~d}$ & 2,21 & $\mathrm{~K}$ & 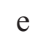 & 1,82 & G & $\mathrm{f}$ & 3,19 \\
\hline 0577337 & 6,13 & $\mathrm{C}$ & $\mathrm{a}$ & 3,98 & I & b & 3,17 & $\mathrm{~L}$ & $\mathrm{c}$ & 3,20 & K & $\mathrm{c}$ & 1,77 & $\mathrm{~N}$ & $\mathrm{~d}$ & 0,67 & $\mathrm{~N}$ & 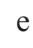 & 1,69 & G & u & 2,94 \\
\hline 0009035 & 3,80 & $\mathrm{~J}$ & $\mathrm{a}$ & 3,49 & $\mathrm{~J}$ & b & 2,74 & $\mathrm{M}$ & $\mathrm{c}$ & 3,89 & I & $\mathrm{a}$ & 2,40 & $\mathrm{M}$ & $\mathrm{d}$ & 1,21 & $\mathrm{M}$ & $\mathrm{f}$ & 2,04 & $\mathrm{~F}$ & e & 2,80 \\
\hline Médias & 5,12 & & & 4,66 & & & 4,55 & & & 4,50 & & & 3,79 & & & 3,68 & & & 2,41 & & & 4,10 \\
\hline
\end{tabular}

*médias seguidas de mesma letra maiúscula e mesma letra minúscula não diferem na coluna e na linha, respectivamente, pelo teste de Scoot e Knoot, a 5\% de probilidade. 
sorgo granífero do Brasil foi menor que 2,5 t.ha1. No Nordeste, a produtividade foi menor que 2 t.ha- ${ }^{-1}$, mostrando que como existe potencial a ser explorado por esses genótipos.

$\mathrm{O}$ resultado da interação genótipo $\mathrm{x}$ ambiente foi semelhante ao do trabalho de Silva et al. (2009), que avaliaram a interação entre cultivares de sorgo granífero em três ambientes, no Sudoeste goiano (Montividiu, Rio Verde e Santa Helena). Oliveira et al. (2002) também observaram interação significativa entre genótipos e ambientes, ao avaliarem cultivares comerciais de sorgo nos municípios de Coronel Pacheco - MG e Lavras - MG.

Uma cultivar que pode ajustar seu comportamento fenotípico para alta produtividade e estabilidade para um local e ano em particular é dita estável ou bem adaptada (Bueno et al., 2006). Allard \& Bradshaw (1964) discutiram os mecanismos que promovem a estabilidade da produção e concluíram que existem duas maneiras de escapar da interação G x A: a cultivar pode ser composta por um grande número de genótipos, adaptados a diferentes ambientes, e os próprios indivíduos podem ser bem adaptados e cada membro da população é bem adaptado em vários ambientes.

\section{Shelbourne \& Campbell} ressaltam que existem dois problemas ou tarefas importantes relacionadas com a interação genótipo x ambientes. A primeira seria predizer os fatores ambientais locais que estejam aumentando a interação e quais os que podem ser agrupados em regiões onde a interação seja mínima. A segunda seria selecionar populações e genótipos para esses diferentes estratos, que sejam bem adaptados a todos os locais.

Em análises de genótipos, principalmente de base genética estreita, em fases finais de um programa de melhoramento, é imprescindível que as condições de manejo sejam bastante similares às da região avaliada. No caso do sorgo granífero, que é uma cultura destinada principalmente à safrinha, deve-se levar em consideração como será a estratégia para a sucessão de culturas da região, pois esta requer uma análise minuciosa da época ideal de plantio. O objetivo é obter uma cultivar com bom desempenho e que este seja estável no decorrer dos anos, ou seja, tenha pouca passividade com os efeitos da interação de genótipos por ambientes.

Ao avaliar a estabilidade fenotípica foi observado que com $75 \%$ de confiabilidade os genótipos 0307689, 0307671, 1G220 0307343, 1G150, 0307363, BRS 308, 0009061, 9920045, BRS 310, 0307541 0441347, 0144015, 0307421 e 0307401, na pior das hipóteses teriam rendimento de 23,$47 ; 23,38 ; 22,62$; 16,$25 ; 10,56 ; 9,6 ; 9,14 ; 8,71 ; 3,96 ; 3,73 ; 3,44$; 2,$54 ; 2,48 ; 1,35$ e $0,03 \%$ superiores a média ambiental, respectivamente (Tabela 5). 
TABELA 5. Estimativa da estabilidade de Acordo com o modelo de Annicchiarico (1992) para rendimento de grãos de 25 genótipos de sorgo avaliados em sete ambientes.

\begin{tabular}{cccc}
\hline Genótipos & i. & $\mathbf{s}_{\mathbf{i}}$ & $\mathbf{I}_{\mathbf{i}}$ \\
\hline 0307689 & 123,47 & 7,61 & 123,47 \\
0307671 & 123,38 & 26,99 & 123,38 \\
$1 \mathrm{G} 220$ & 122,62 & 19,44 & 122,62 \\
0307343 & 116,25 & 14,29 & 116,25 \\
1 G150 & 110,56 & 25,22 & 110,56 \\
0307363 & 109,60 & 13,07 & 109,60 \\
BRS 308 & 109,14 & 30,61 & 109,14 \\
0090061 & 108,71 & 21,20 & 108,71 \\
9920045 & 103,96 & 16,86 & 103,96 \\
BRS 310 & 103,73 & 15,23 & 103,73 \\
0307541 & 103,44 & 10,68 & 103,44 \\
0441347 & 102,54 & 8,34 & 102,54 \\
0144015 & 102,48 & 11,02 & 102,48 \\
0307421 & 101,35 & 20,50 & 101,35 \\
0307401 & 100,03 & 21,75 & 100,03 \\
0144013 & 99,84 & 12,79 & 99,84 \\
0307167 & 99,20 & 30,70 & 99,20 \\
0307561 & 93,88 & 14,88 & 93,88 \\
Dow 822 & 92,24 & 8,81 & 92,24 \\
0307511 & 90,45 & 20,74 & 90,45 \\
0577335 & 84,86 & 18,26 & 84,86 \\
0577393 & 84,69 & 17,22 & 84,69 \\
0307509 & 76,78 & 12,82 & 76,78 \\
0577337 & 68,70 & 31,43 & 68,70 \\
0090035 & 68,08 & 18,33 & 68,08 \\
\hline
\end{tabular}

\section{Conclusão}

O rendimento de grãos foi extremamente dependente do ambiente e apenas o genótipo 0307167 teve desempenho superior em mais de um ambiente.

Os genótipos 0307167 e $1 \mathrm{G} 150$ se mostram tolerantes à saturação por alumínio.
Quanto a estabilidade de rendimento de grãos se destacaram os híbridos experimentais 0307689, 0307671, 0307343, 1G150, 0307363, 0009061,9920045, 0307541,0441347,0144015, 0307421 e 0307401 e os híbridos comerciais 1G220, BRS 310 e BRS 308 que, mesmo na pior das hipóteses, superariam o rendimento médio dos genótipos nos ambientes avaliados. 


\section{Literatura Citada}

ABREU, S. C. A.; FERREIRA, D. F.; GURGEL, F. L.; ABREU, A F. B. Extensão bivariada do índice de confiabilidade univariado para avaliação da estabilidade fenotípica. Ciência Agrotecnologia, Lavras, v. 28, n. 5, p. 10471052, set./out. 2004.

AGRITEMPO. Disponível em: <www. agritempo.gov.br>. Acesso em: 19 set. 2010.

ALLARD, R. W.; BRADSHAW, A. D. Implications of genotype-environment interactions in applied plant breeding. Crop Science, Madison, v. 4, n. 2, p. 503-507, 1964.

ALVES, V. M. C.; VASCONCELLOS, C. A.; FREIRE, F. M.; PITTA, G. V. E.; FRANÇA, G. E. de. Sorgo. In: RIBEIRO, A. C.; GUIMARÃES, P. T. G.; ALVAREZ, V. V. H. (Ed.). Recomendação para uso de corretivos e fertilizantes em Minas Gerais: 5a aproximação. Viçosa: Comissão de Fertilidade do Solo do Estado de Minas Gerais, 1999. p. 325-327.

ANNICCHIARICO, P. Cultivar adaptation and recommendation from alfalfa trials in Northern Italy. Journal Genetics and Breeding, Roma, v. 46, n. 1, p. 269-278, Mar. 1992.

BANZATO, D. A.; KRONKA, S. N. Experimentação agrícola. Jaboticabal: UNESP, 1992. 247 p.

BUENO, L. C. S.; MENDES, A. N. G.; CARVALHO, S. P. Melhoramento genético de plantas: princípios e procedimentos. 2. ed. Lavras: UFLA, 2006. 282 p.

CARNEIRO, P. C. S. Novas metodologias de análise da adaptabilidade e estabilidade de comportamento. 1998. 155 f. Tese (Doutorado em Genética e Melhoramento) - Universidade Federal de Viçosa, Viçosa, MG.

CRUZ C. D.; REGAZZI A. J. 2001. Modelos biométricos aplicados ao melhoramento genético. 2.ed. rev. Viçosa: UFV. 390p.

CRUZ, C. D. Programa Genes - Estatística experimental e matrizes. Viçosa, MG: UFV, 2006. 285 p.

EBERHART, S. A.; RUSSELL, W. A. Stability parameters for comparing varieties. Crop Science, Madison, v. 6, p. 36-40, 1966.

ELIAS H. T.; SCAPIM, C.A. RODOVALHO, M. de A.; ROYER, M. R.; MORA, F.; BARRETO, R. R. Análise de estabilidade de genótipos de feijoeiro no Estado de Santa Catarina. Acta Scientiarum, Agronomy, Maringá, v. 27, n. 4, p. 623-628, Oct./Dec. 2005.

FERREIRA, D. F. Estabilidade. ULFA, Disponível em: <http://www.dex.ufla. br/ danielff/softwares.htm>. Acesso em: 10 out 2009.

FIGUEIREDO, A. Perspectivas da cultura de sorgo. Newsletter Monsanto em Campo, v. 3, n. 16, jul. 2007. Disponível em: <http://www. monsanto.com.br/monsanto/brasil/newsletter/ cientistas/16_2007Julho/08agricultura.asp $>$. Acesso em: 30 mar 2009.

IBGE. Disponível em: <http://www.ibge.gov.br >. Acesso: 19 set. 2010 .

MAGAlhãeS, P. C.; DURÃES F. O. M.; RODRIGUES, J. A. S. Cultivo do sorgo: ecofisiologia. In: RODRIGUES, J. A. S. (Ed.). Cultivo do sorgo. 5. ed. Sete Lagoas: Embrapa

Revista Brasileira de Milho e Sorgo, v.9, n.1, p. 51-64, 2010

Versão impressa ISSN 1676-689X / Versão on line ISSN 1980-6477 - http://www.abms.org.br 
Milho e Sorgo, 2009. (Embrapa Milho e Sorgo. Sistemas de produção, 2).. Disponível em : < http://www.cnpms.embrapa.br/publicacoes/ sorgo_4_ed/ecofisiologia.htm>. Acesso em: 13 set. 2010 .

OLIVEIRA, J. S.; FERREIRA, R. P.; CRUZ, C. D. PEREIRA, A. V; BOTREL, M. A.; VON PINHO, R. G; RODRIGUES, J. A. S.; LOPES, F. C. F.; MIRANDA, J. E. C. Adaptabilidade e estabilidade em cultivares de sorgo. Revista Brasileira de Zootecnia, Viçosa, v.31, n. 2, p. 883-889, 2002. Suplemento.

SANTOS, F. G.; RODRIGUES, J. A. S.; SCHAFFERT, R. E.; CASELA, C. R.; FERREIRA, A. S. Híbrido de sorgo granífero

BRS 308. Sete Lagoas: Embrapa Milho e Sorgo, 2007. 4 p. (Embrapa Milho e Sorgo.Comunicado Técnico,146).

SCAPIM, C. A.; OLIVEIRA, V. R.; BRACCINI, A. L.; CRUZ C. D.; ANDRADE, C.A.B.; VIDIGAL, M. C. G. Yield stability in maize (Zea mays L.) and correlations among the parameters of the Eberhart and Russell, Lin and Binns and Huehn models. Genetics and Molecular Biology, Ribeirão Preto, v. 23, n. 2, p. 387-393, 2000.

SCOTT, A. J.; KNOTT, M. A. A cluster analysis method for grouping means in the analyisi of variance. Biometrics, Raleigh, v. 30, n. 3, p. 507-512, 1974.

SHELBOURNE, C. J. A.; CAMPBELL, R. K. The impact of genotype environment interactions on tree improvement strategy. In: IUFRO JOINT MEETING ON ADVANCED GENERATION BREEDING, 1976, Bordeaux. Proceedings... Bordeaux,: INRA, 1976.

SILVA, A. G. Avaliação de cultivares de sorgo granífero na safrinha no sudoeste do estado de Goiás. Pesquisa Agropecuária Tropical, Goiânia, v. 39, n. 2, p. 168-174, abr./jun. 2009.

WRICKE, G. Zur Berechnung der Ökovalenz bei Sommerweizen und Hafer. Zeitschrift für Pflanzenzüchtung, Berlin, v. 52, n. 1, p. 127138, 1965. 